\title{
DISCOVERING HIDDEN PATTERNS IN DATA
}

ONE OF THE GREATEST CHALLENGES IN MODERN SCIENCE IS HOW TO GET USEFUL CONCLUSIONS FROM MASSIVE DATASETS. DR ERIC CHI, OF NORTH CAROLINA STATE UNIVERSITY IN THE US, DEVELOPS INNOVATIVE WAYS TO DISCOVER THE INFORMATION HIDDEN WITHIN DATA, HELPING WITH A RANGE OF SOCIETAL ISSUES

\section{TALK LIKE A DATA SCIENTIST}

DATA - anything that can be recorded or measured

DATA CLUSTERING - dividing data points into groups, where data points within each group are more similar to each other than those in other groups

DATA CUBE - a multi-dimensional array of values

\section{INFORMATION EXPLOSION - the}

rapid increase in the amount of available data, brought about by technological progress in areas such as computing power and the internet

NEUROSCIENCE - the scientific study of the nervous system

\section{OPEN SOURCE - software where the} original source code is made freely available

STATISTIC - computed summarisation of data that helps interpret the data

VARIABLE - a factor whose value changes in a scientific experiment
In our modern age of computing, we have the tools to collect massive amounts of data on all kinds of subject matters, but the challenge is building the tools to interpret this data to draw meaningful conclusions. At the Statistics Department of North Carolina State University, Assistant Professor Dr Eric Chi is tackling this issue and using mathematical concepts to tease information out of complex datasets.

\section{WHEN DATA GETS COMPLICATED}

One of Eric's current projects involves finding patterns in data cubes. An example of a data cube is a three-dimensional dataset - each dimension could have multiple variables. Generally, humans are better at seeing patterns in two dimensions, such as a graph with $x$ and $y$ axes. When we add more dimensions, things start to get complicated.

Neuroscience is one scientific field where new recording techniques have meant that the quantity of data available to us has exploded in recent decades. For instance, the activity of neurons (nerve cells) in the brain can be measured using three dimensions: time, the specific neuron involved, and the experimental conditions involved. This can be stored in three-dimensional space to form a data cube. "We've been working on methods to analyse such data," says Eric. "We want to see if we can identify neuronal firing patterns and how they change over time, under different experimental conditions. This will help neuroscientists better understand the brain."

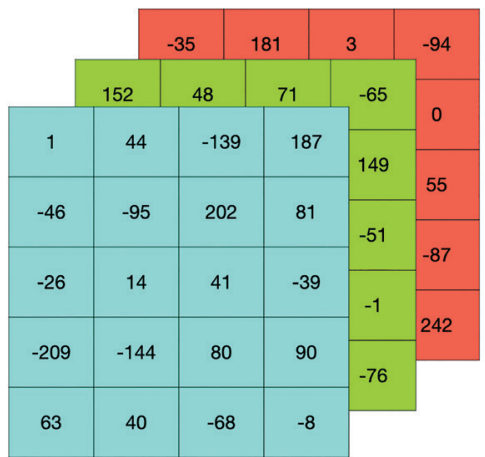

An example of a 3-way multidimensional array or data cube.

SORTING BY SIMILARITY

"The idea of clustering is to group a collection of datapoints in such a way that members in the same group are very similar to each other, while very different from members in other groups," says Eric. This helps us to visualise data in separate 'clusters', which then helps us to understand the data. For instance, if you collect data on environmental and genetic factors of individuals, you can cluster these observations to make progress towards understanding who is more likely to get a certain disease and to gauge how much individuals might be at risk. Clustering is an example of exploratory data analysis - a first step in developing models for making predictions that can guide clinical decision making.

It can also help us to understand more complex data. "Suppose you work for an online streaming 



\section{HOW DID ERIC BECOME A DATA SCIENTIST?}

0

WHAT INSPIRED YOU TO CHOOSE YOUR CAREER?

If I had to blame one person for setting me on this career path, it would be my high school geometry teacher! He shared his delight in elegant proofs, with all of his students, and helped me develop my interests and tastes early on.

WHAT SKILLS HAVE YOU FOUND USEFUL FOR YOUR AREA OF EXPERTISE?

Statistics is a very broad field, but my research focuses on machine learning and algorithm development. To get into this particular area, courses like real analysis, linear algebra, and probability are useful for the mathematical side of things. There is also the computing element, where courses on optimisation, coding and software engineering are extremely helpful. Together, these provide a solid foundation for learning more specific skills.

WHAT INSPIRES YOU TO MENTOR FOR THE DST PROGRAMME? I had a lot of good mentors throughout high school, college, and beyond. I wouldn't be where I am today without them. It's rewarding to play a small part in getting young students interested and curious about maths, statistics and data science.
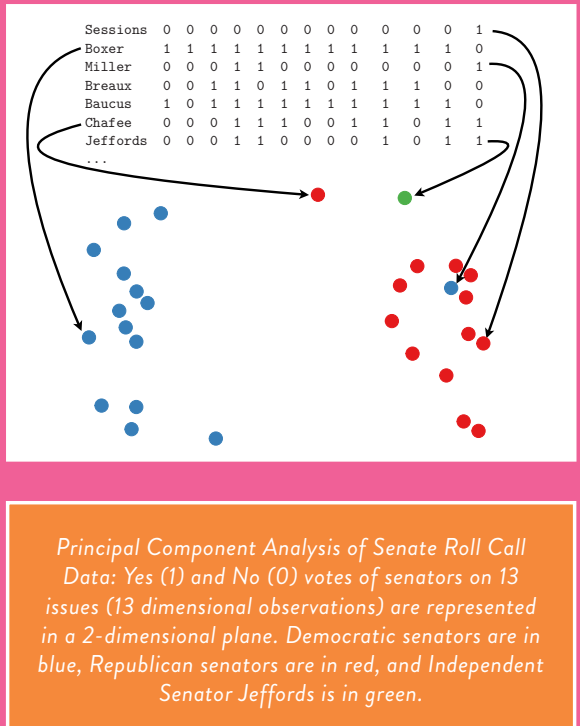

\section{ERIC'S TOP TIPS} FOR STUDENTS

1 Don't be afraid to try new things and to fail sometimes.

2 There are a lot of good free resources out there that will help you with your career. For instance, a free coding course for Python can be invaluable for getting into machine learning.

3 Take ownership of your future but be patient with yourself. It can take time to figure things out but it's important to explore.
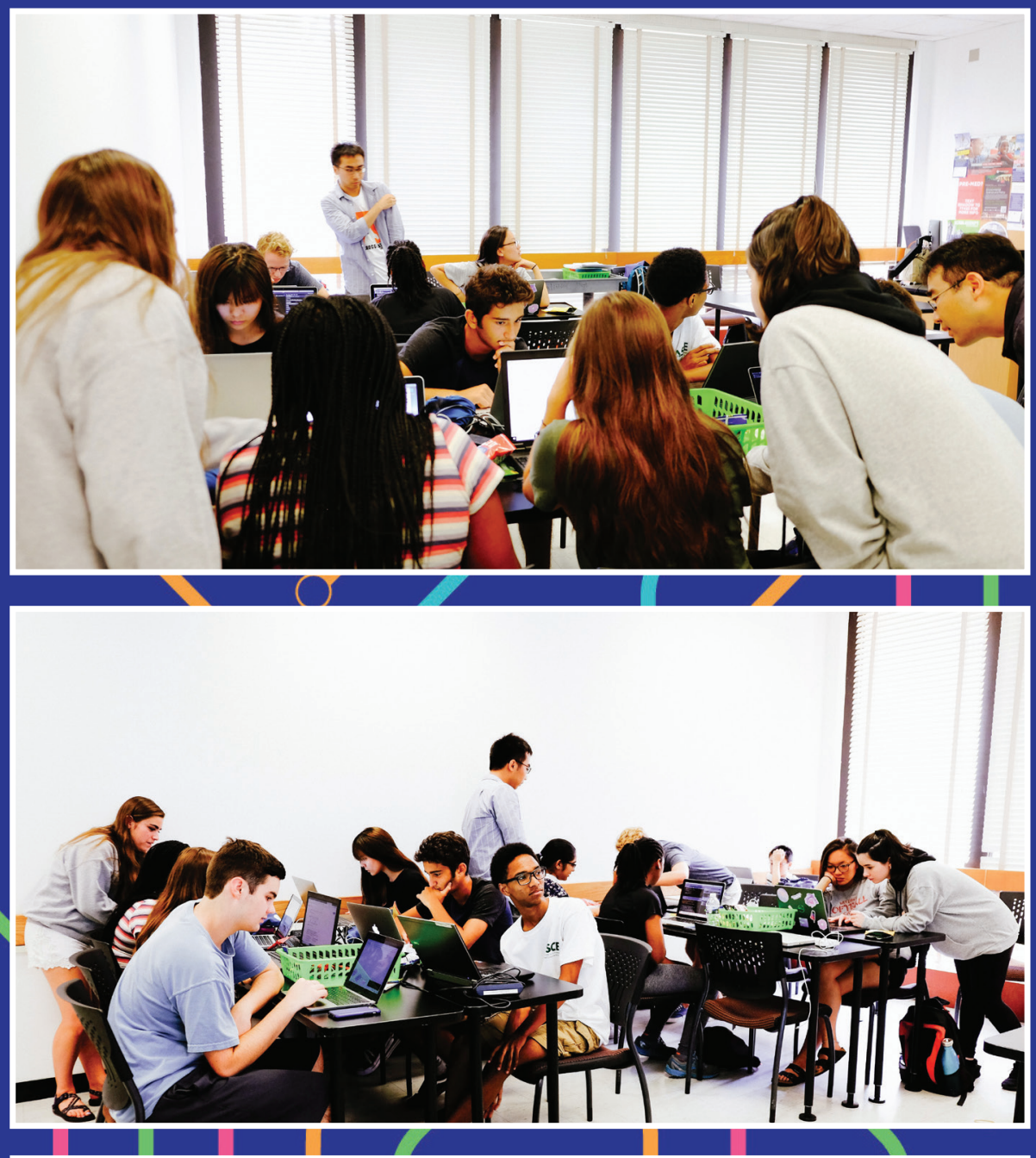

The first cohort of DST participants work on a project during a bootcamp.

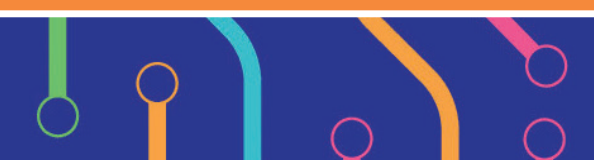

